Article

\title{
A Novel Non-Enzymatic Electrochemical Hydrogen Peroxide Sensor Based on a Metal-Organic Framework/Carbon Nanofiber Composite
}

\author{
Yijun Fu ${ }^{1,2}$, Jiamu Dai ${ }^{1,2}$, Yan Ge ${ }^{1,2}$, Yu Zhang ${ }^{1,2}$, Huizhen Ke ${ }^{3, * \mathbb{C}}$ and Wei Zhang ${ }^{1,2, * \mathbb{C}}$ \\ 1 College of Textile and Clothing, Nantong University, Nantong 226019, China; fuyj@ntu.edu.cn (Y.F.); \\ jmdai@ntu.edu.cn (J.D.); ntdxgeyan@126.com (Y.G.); z.yu@ntu.edu.cn (Y.Z.) \\ 2 National \& Local Joint Engineering Research Center of Technical Fiber Composites for Safety and Protection, \\ Nantong 226019, China \\ 3 Fujian Key Laboratory of Novel Functional Textile Fibers and Materials, Minjiang University, \\ Fuzhou 350108, China \\ * Correspondence: kehuizhen2013@163.com (H.K.); zhangwei@ntu.edu.cn (W.Z.); \\ Tel.: +86-591-8376-0411 (H.K.); +86-513-8501-2837 (W.Z.)
}

Received: 31 August 2018; Accepted: 2 October 2018; Published: 6 October 2018

\begin{abstract}
A co-based porous metal-organic framework (MOF) of zeolitic imidazolate framework-67 (ZIF-67) and carbon nanofibers (CNFs) was utilized to prepare a ZIF-67/CNFs composite via a one-pot synthesis method. Scanning electron microscopy (SEM), energy dispersive X-ray spectroscopy (EDX), and X-ray diffraction (XRD) were employed to investigate the morphology, structure, and composition of the resulting composite. A novel high-performance non-enzymatic electrochemical sensor was constructed based on the ZIF-67/CNFs composite. The ZIF-67/CNFs based sensor exhibited enhanced electrocatalytic activity towards $\mathrm{H}_{2} \mathrm{O}_{2}$ compared to a pure ZIF-67-based sensor, due to the synergistic effects of ZIF-67 and CNFs. Meanwhile, chronoamperometry was utilized to explore the detection performance of the sensor. Results showed the sensor displayed high-efficiency electrocatalysis towards $\mathrm{H}_{2} \mathrm{O}_{2}$ with a detection limit of $0.62 \mu \mathrm{M}(\mathrm{S} / \mathrm{N}=3)$, a sensitivity of $323 \mu \mathrm{A} \mathrm{mM} \mathrm{m}^{-1} \mathrm{~cm}^{-2}$, a linear range from 0.0025 to $0.19 \mathrm{mM}$, as well as satisfactory selectivity and long-term stability. Furthermore, the sensor demonstrated its application potential in the detection of $\mathrm{H}_{2} \mathrm{O}_{2}$ in food.
\end{abstract}

Keywords: metal-organic framework; ZIF-67; non-enzymatic sensor; carbon nanofiber; hydrogen peroxide

\section{Introduction}

Hydrogen peroxide $\left(\mathrm{H}_{2} \mathrm{O}_{2}\right)$, as an important industrial chemical, has been widely applied in various fields, including food production, medicine manufacture, clinic treatment, etc [1-3]. The detection of $\mathrm{H}_{2} \mathrm{O}_{2}$ in food is of great importance because it participates in various cellular metabolism pathways of the human body and an abnormal level of $\mathrm{H}_{2} \mathrm{O}_{2}$ may lead to severe diseases such as cardiovascular disorders, Alzheimer's disease and even cancer [4-6]. Therefore, the development of fast and accurate methods for $\mathrm{H}_{2} \mathrm{O}_{2}$ detection has become a research hotspot. There are various kinds of methods for monitoring $\mathrm{H}_{2} \mathrm{O}_{2}$, such as chemiluminescence, titrimetry, electrochemistry, spectrometry and high performance liquid chromatography [7-11]. Among these methods, the electrochemical technique using natural enzymes is becoming increasingly popular due to its intrinsic advantages including simple operation, low cost, good selectivity, and high sensitivity [12,13]. Nevertheless, the performance of enzyme-based electrochemical sensors is mainly dependent on the enzyme activity, which is highly vulnerable to environmental factors like $\mathrm{pH}$, temperature, etc [14]. Thus, novel 
non-biological materials have been exploited instead of enzymes in electrochemical sensors for $\mathrm{H}_{2} \mathrm{O}_{2}$ detection $[10,12,13,15]$.

Metal organic frameworks (MOFs), which are novel three dimensional organic-inorganic hybrids self-assembled by metal ions and organic ligands, have seen explosive growth in a variety of application fields during the past decades [16]. Generally, MOFs possess various topologies, and their morphology or constitution can be adjusted through the appropriate selection of metal ions, ligands, or synthesis methods [17]. These characteristics enable MOFs to be applied in gas storage, drug delivery, separation, catalysis, sensing, etc [18-22]. In this work, a Co-based porous MOF [Co(mIM) $\left.{ }_{2}\right]_{n}$ (denoted as ZIF-67, $\mathrm{mIM}=2$-methylimidazole) was selected as the modification material of an electrochemical sensor due to the favorable electrocatalytic property of $\mathrm{Co}^{2+}$ inside ZIF-67 towards $\mathrm{H}_{2} \mathrm{O}_{2}$ [23]. The crystal structure of ZIF-67 is shown in Scheme 1. The largest cage is shown with $\mathrm{CoN}_{4}$ in pink polyhedra, and the links in ball-and-stick presentation. The yellow ball indicates space in the cage. $\mathrm{H}$ atoms are omitted for clarity (C, gray; N, blue) [24].

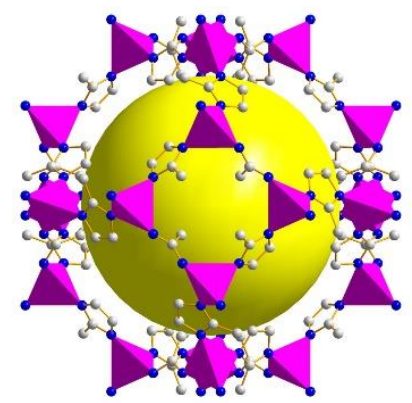

Scheme 1. Crystal structure of ZIF-67.

Though the ZIF-67 exhibits favorable electrocatalytic ability towards $\mathrm{H}_{2} \mathrm{O}_{2}$, its poor conductivity restricts its application in electrochemical $\mathrm{H}_{2} \mathrm{O}_{2}$ sensors. To solve this problem, some researchers synthesized MOFs/carbon nanomaterials composites, e.g., $\mathrm{MOF} /$ reduced graphene oxide (MOF/rGO) composite, to improve the conductivity of MOF, and it was successfully applied in the high-efficiency monitoring of $\mathrm{H}_{2} \mathrm{O}_{2}[16,17,25]$. Among all carbon materials, carbon nanofibers (CNFs) have attracted a lot of attention because they are easily synthesized and possess many more edge sites compared with carbon nanotubes (CNTs). It is widely accepted that CNFs exhibit outstanding conductivity, high porosity, huge specific surface, as well as excellent mechanical strength. Therefore, CNFs are good candidate for the development of electrochemical sensors or biosensors [26].

In this work, ZIF-67 and CNFs were jointly selected to synthesize a MOF/CNFs composite, namely ZIF-67/CNFs, which was further employed to construct a novel non-enzymatic electrochemical sensor. Afterwards, a series of electrochemical characterizations were carried out to investigate the electrochemical properties of ZIF-67/CNFs composite. In addition, the selectivity, stability, and practical application of ZIF-67/CNFs based electrochemical sensor were also studied to evaluate its potential application in $\mathrm{H}_{2} \mathrm{O}_{2}$ detection.

\section{Results and Discussions}

\subsection{Morphology, Chemical Component, and EIS Analysis}

Figure 1 shows the SEM images of CNFs, ZIF-67 nanocrystals, and ZIF-67/CNFs composite. Since CNFs were ground before the synthesis procedure, numerous short fibers are randomly distributed in Figure 1a. It can be observed that the surfaces of fibers were smooth, with no impurities on them. The diameter of the CNFs ranged from $213 \mathrm{~nm}$ to $524 \mathrm{~nm}$, with an average diameter of $286 \mathrm{~nm}$. It can be seen from Figure $1 \mathrm{~b}$ that the ZIF-67 exhibited a dispersed rhombic dodecahedral nanocrystal morphology, which was in accordance with another report [27]. Moreover, the rhombic facet of ZIF-67 was well-defined and its edge was clearly visible, indicating the perfect crystalline structure of the 
synthesized ZIF-67 nanocrystals. The size of ZIF-67 nanocrystals was from 317 nm to $1.2 \mu \mathrm{m}$, with a mean particle size of $706 \mathrm{~nm}$. Figure 1c presents the morphology of the ZIF-67/CNFs composite. It can be clearly seen that the ZIF-67 nanocrystals and CNFs were evenly mixed together, with some ZIF-67 nanocrystals attached on the surfaces of CNFs. This may be ascribed to the attractive forces between CNFs and ZIF-67 nanocrystals. Herein, the CNFs play the role of a "molecular wire" which could accelerate the electron transfer rate between ZIF-67 and electrode surface, leading to an improved electrocatalytic activity of ZIF-67/CNFs composite.
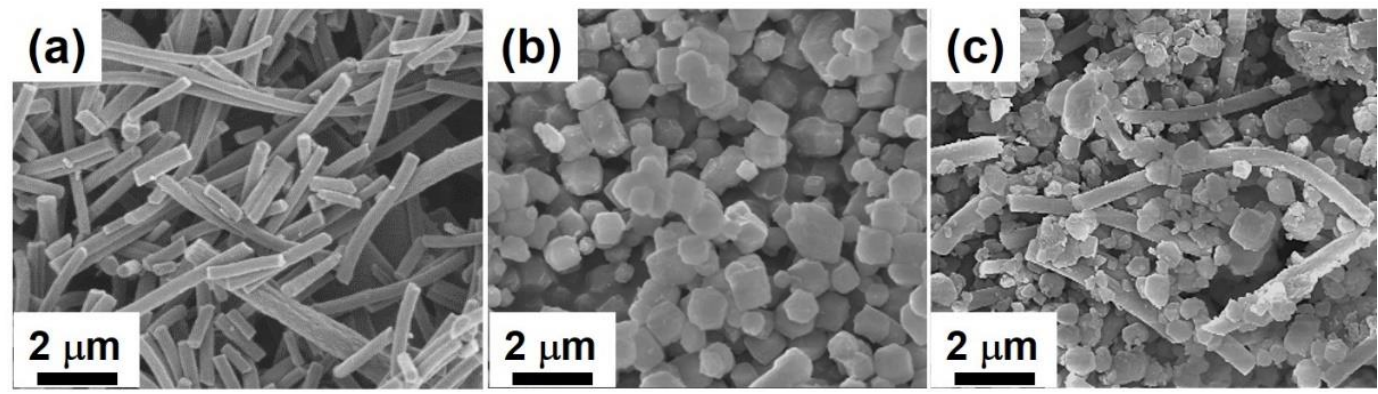

Figure 1. SEM images of (a) CNFs; (b) ZIF-67 nanocrystals; and (c) ZIF-67/CNFs composite.

Energy-dispersive spectroscopic (EDS) mapping was conducted to investigate the distribution of ZIF-67 nanocrystals in the ZIF-67/CNFs composite. As illustrated in Figure 2, it was apparent that the elements of $\mathrm{C}, \mathrm{O}, \mathrm{N}$ and Co were uniformly and densely dispersed in the ZIF-67/CNFs composite. Meanwhile, the existence of $\mathrm{N}$ and Co elements demonstrated that the ZIF-67 nanocrystals were successfully synthesized and introduced in the composite. In addition, considering the $\mathrm{N}$ and $\mathrm{Co}$ elements did not exist in CNFs, and these two elements were evenly dispersed in the EDS mapping picture, this suggested that the ZIF-67 nanocrystals were equally distributed in the ZIF-67/CNFs composite rather than aggregated.

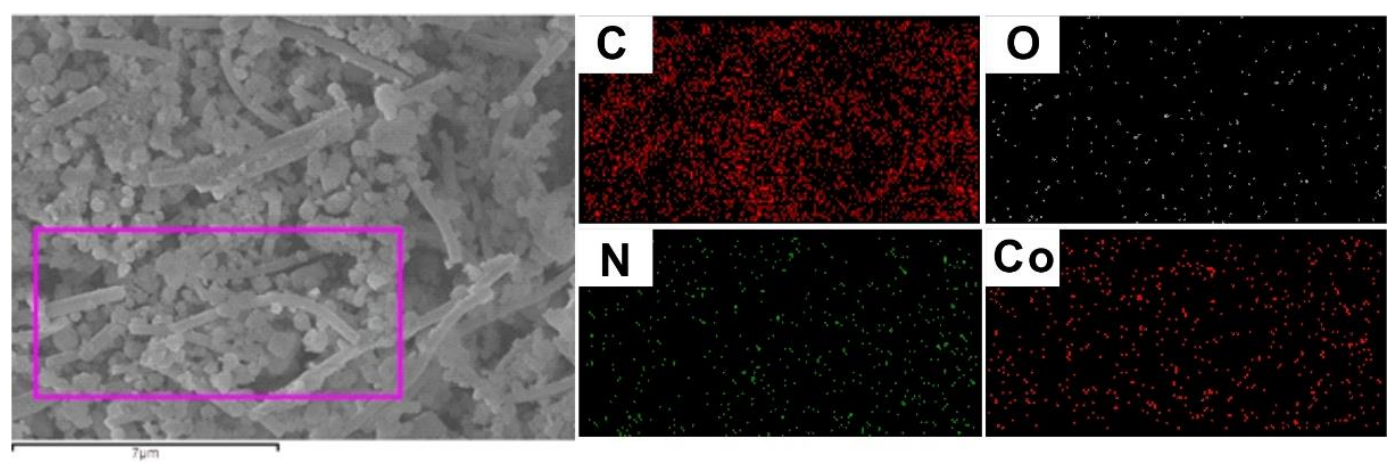

Figure 2. Element mapping images of the ZIF-67/CNFs composite.

X-ray diffraction (XRD) characterization was further employed to study the chemical components of ZIF-67/CNFs. Figure 3 shows the XRD patterns of CNFs, synthesized ZIF-67, and ZIF-67/CNFs composite. It can be clearly seen from Figure 3 that the CNFs displayed an apparent and wide diffraction peak at around $25.6^{\circ}$, which corresponded to the (002) crystalline plane of carbon material [28]. For the synthesized pure ZIF-67, it showed a pattern coincident with the simulated ZIF-67 one. Sharp peaks were clearly observed at the diffraction peaks of $7.3^{\circ}, 12.4^{\circ}$, and $17.7^{\circ}$, which were assigned to the (110), (211), and (222) planes of ZIF-67 crystals, respectively [29]. Notably, the XRD pattern of ZIF-67/CNFs composite displayed the diffraction peaks of both CNFs and ZIF-67, indicating the successful synthesis of ZIF-67/CNFs composite. 


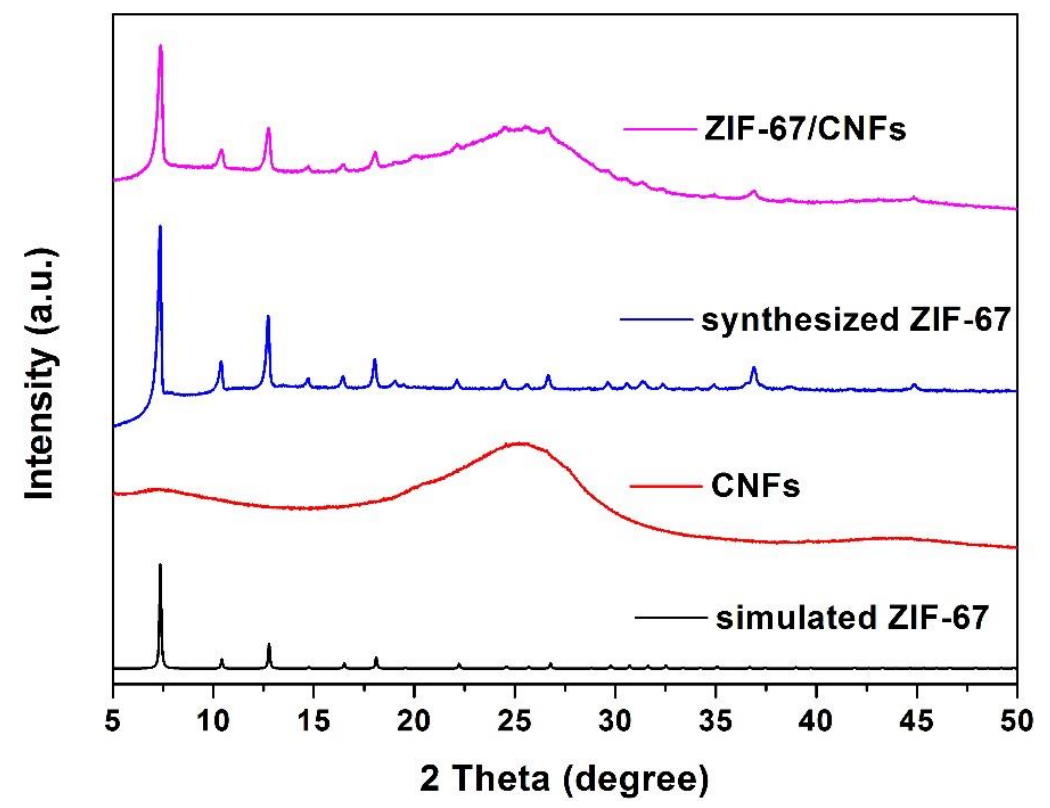

Figure 3. XRD patterns of simulated ZIF-67, CNFs, synthesized ZIF-67, and ZIF-67/CNFs composite.

Electrochemical impedance spectroscopy (EIS) is an efficient method to explore the interface resistance of a modified electrode. In order to evaluate the potential application of ZIF-67/CNFs as an efficient electrocatalyst, it is essential to investigate the electron transfer resistance (Ret) of the ZIF-67/CNFs modified electrode. Figure 4 compares the Nyquist plots of different modified electrodes. It is well known that the semicircle diameter of the Nyquist plots corresponds to the value of Ret, and the Ret controls the electron transfer kinetics of the redox electrochemical probe at the electrode interface. As shown in Figure 4, the Ret value of bare GCE was $149 \Omega$, while the Ret value of ZIF-67/GCE was as high as $1206 \Omega$. However, the Ret value of ZIF-67/CNFs/GCE decreased to $876 \Omega$ after the addition of CNFs. This indicates that the involvement of CNFs could significantly reduce the interface resistance of the modified electrode, leading to an improved conductivity.

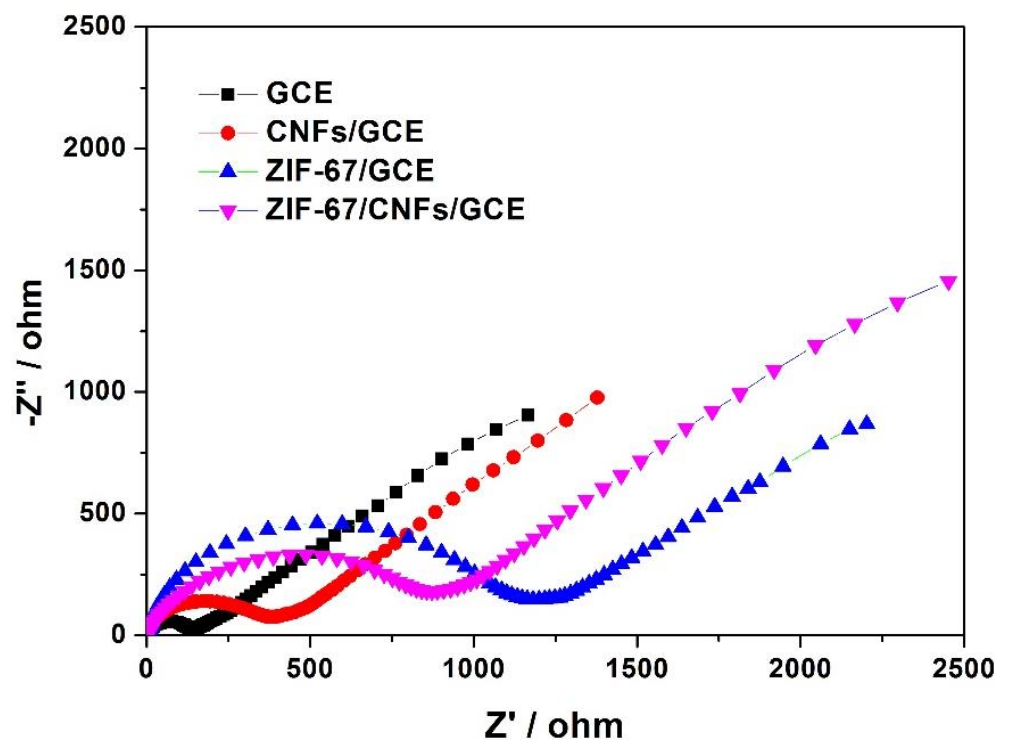

Figure 4. Nyquist plots for bare GCE, CNFs/GCE, ZIF-67/GCE and ZIF-67/CNFs/GCE in a solution of $0.1 \mathrm{M} \mathrm{KCl}$ containing $5 \mathrm{mM} \mathrm{Fe}(\mathrm{CN})_{6}{ }^{3-/ 4-}$ with the potential of $0.2 \mathrm{~V}$, the frequency range from $0.01 \mathrm{~Hz}$ to $100,000 \mathrm{~Hz}$ and signal amplitude of $5 \mathrm{mV}$. 


\subsection{Electrocatalytic Activity for $\mathrm{H}_{2} \mathrm{O}_{2}$ Reduction}

Figure 5a shows the cyclic voltammograms (CVs) of bare GCE, CNFs/GCE, ZIF-67/GCE, and ZIF-67/CNFs/GCE in $0.1 \mathrm{M} \mathrm{NaOH}$ solution containing $25 \mu \mathrm{M} \mathrm{H}_{2} \mathrm{O}_{2}$. The peaks at $-0.6 \mathrm{~V}$ were ascribed to the reduction reaction of $\mathrm{H}_{2} \mathrm{O}_{2}$. Apparently, CNFs/GCE displayed higher reduction peak current $(44.8 \mu \mathrm{A})$ than bare GCE $(24.3 \mu \mathrm{A})$, indicating the good electrocatalytic activity of CNFs. As for ZIF-67/GCE, it showed a much larger reduction peak current $(81.5 \mu \mathrm{A})$ than that of CNFs/GCE, demonstrating the better electrocatalytic activity of ZIF-67 than CNFs. Interestingly, the reduction peak current of ZIF-67/CNFs/GCE was increased again by $9.1 \mu \mathrm{A}$ in contrast with that of ZIF-67/GCE. The reason of this phenomenon can be ascribed as following: on one hand, the conductivity of the ZIF-67/CNFs composite was enhanced by CNFs; on the other hand, ZIF-67 and CNFs performed a synergistic catalysis role in the whole electrochemical reaction.

Figure $5 \mathrm{~b}$ displays CVs of the ZIF-67/CNFs/GCE in $0.1 \mathrm{M} \mathrm{NaOH}$ solution at different scan rates. As can be seen from the insert of Figure $5 b$, the anodic and cathodic peak currents increased linearly as the scan rate increased from 100 to $350 \mathrm{mV} \mathrm{s}^{-1}$, suggesting a surface controlled electrochemical redox process, which indicated that the ZIF-67/CNFs composites were well immobilized on the electrode surface.

(a)

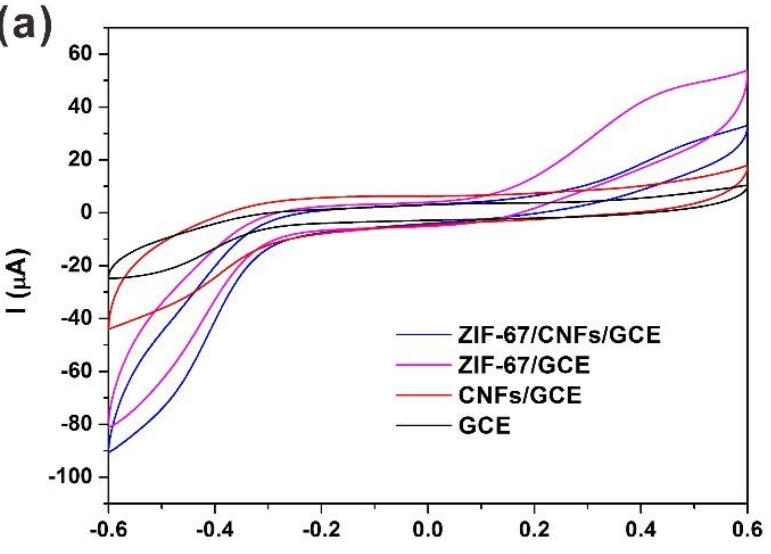

(c)

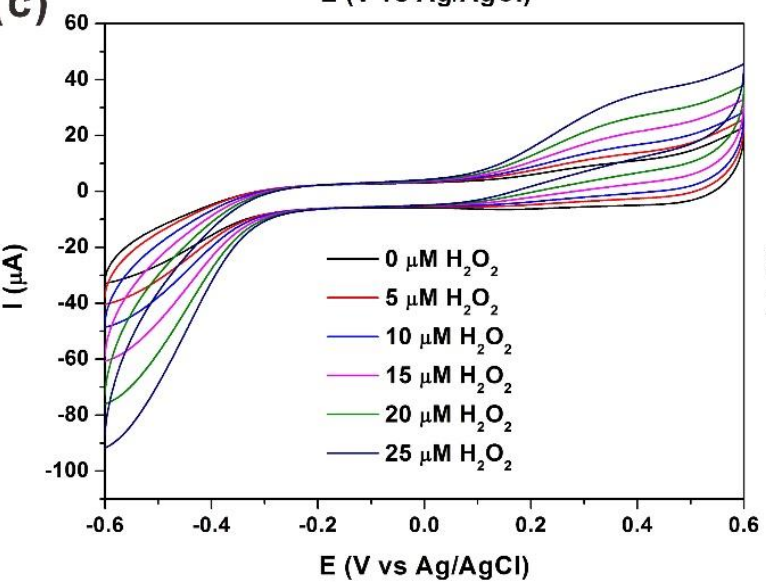

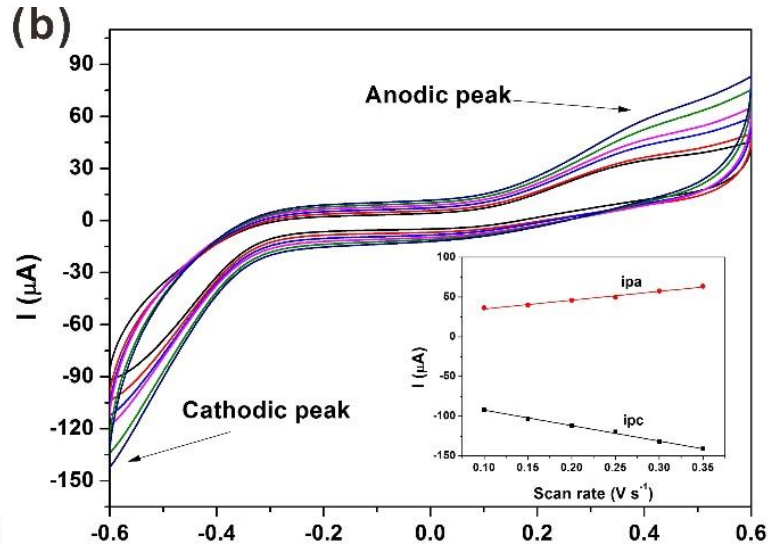

(d)

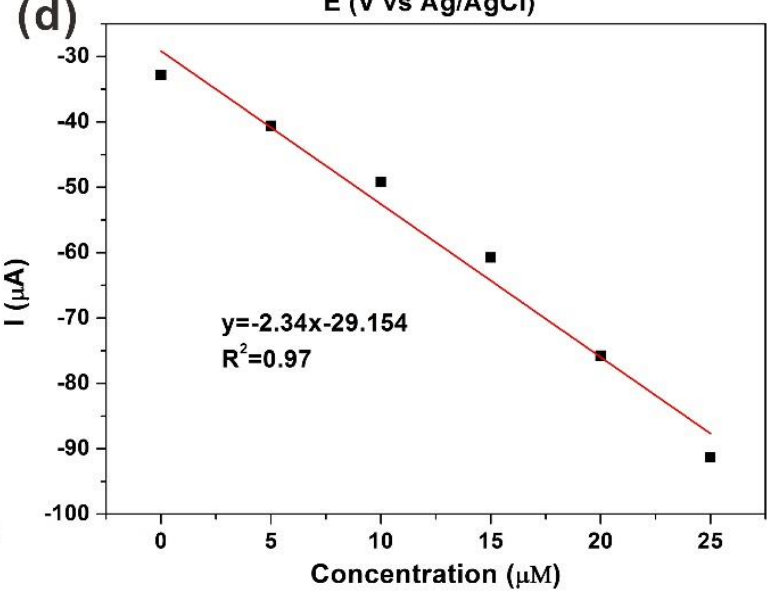

Figure 5. (a) CVs of different electrodes in $0.1 \mathrm{M} \mathrm{NaOH}$ solution containing $25 \mu \mathrm{M} \mathrm{H}_{2} \mathrm{O}_{2}$; (b) CVs of the ZIF-67/CNFs/GCE in $0.1 \mathrm{M} \mathrm{NaOH}$ solution at scan rates of 100, 150, 200, 250, 300, $350 \mathrm{mV} \mathrm{s}^{-1}$ (from inner to outer), respectively, inset: plots of the corresponding anodic and cathodic peak currents vs. scan rate; (c) CVs of the ZIF-67/CNFs/GCE in $0.1 \mathrm{M} \mathrm{NaOH}$ solution with the presence of varied $\mathrm{H}_{2} \mathrm{O}_{2}$ concentrations: $0,5,10,15,20,25 \mu \mathrm{M}$ (scan rate: $100 \mathrm{mV} \mathrm{s}^{-1}$ ); (d) the corresponding calibration curve. 
Figure $5 \mathrm{c}$ shows CVs of the ZIF-67/CNFs/GCE in $0.1 \mathrm{M} \mathrm{NaOH}$ solution with the presence of 0,5 , $10,15,20$, and $25 \mu \mathrm{M}$ of $\mathrm{H}_{2} \mathrm{O}_{2}$. As observed, the cathodic peak current values increased linearly with the concentration of added $\mathrm{H}_{2} \mathrm{O}_{2}$. Moreover, the calibration curve (shown in Figure $5 \mathrm{~d}$ ) also demonstrated the favorable linear relation between cathodic peak current value and $\mathrm{H}_{2} \mathrm{O}_{2}$ concentration. This result revealed that the ZIF-67/CNFs/GCE could find potential application as an electrochemical sensor.

The possible reaction mechanism is illustrated in Scheme 2 and the reaction path for ZIF-67 catalyst towards $\mathrm{H}_{2} \mathrm{O}_{2}$ could be expressed as following equations:

$$
\begin{gathered}
\text { ZIF-67-Co }{ }^{2+}+\mathrm{H}_{2} \mathrm{O}_{2} \rightarrow \text { ZIF-67-Co }{ }^{3+}+\mathrm{H}_{2} \mathrm{O}+\mathrm{O}_{2} \\
\text { ZIF-67-Co } \mathrm{Co}^{3+}+\mathrm{e}^{-} \rightarrow \text { ZIF-67-Co }{ }^{2+}
\end{gathered}
$$

At the beginning of electrochemical reaction, $\mathrm{H}_{2} \mathrm{O}_{2}$ was adsorbed in the pores of $\mathrm{ZIF}-67-\mathrm{Co}^{2+}$. As the reaction continued, the absorbed $\mathrm{H}_{2} \mathrm{O}_{2}$ was reduced into $\mathrm{H}_{2} \mathrm{O}$ and $\mathrm{O}_{2}$, along with the oxidization of ZIF-67-Co $\mathrm{Co}^{2+}$ into ZIF-67-Co ${ }^{3+}$. Last, ZIF-67- $\mathrm{Co}^{3+}$ achieved an electron from electrode to regenerate ZIF-67-Co ${ }^{2+}$. The CNFs existing in the composite membrane on electrode surface not only accelerated the electron transfer rate, but also worked together with ZIF-67 to achieve the synergistic catalysis, resulting in an amplified electrochemical signal.

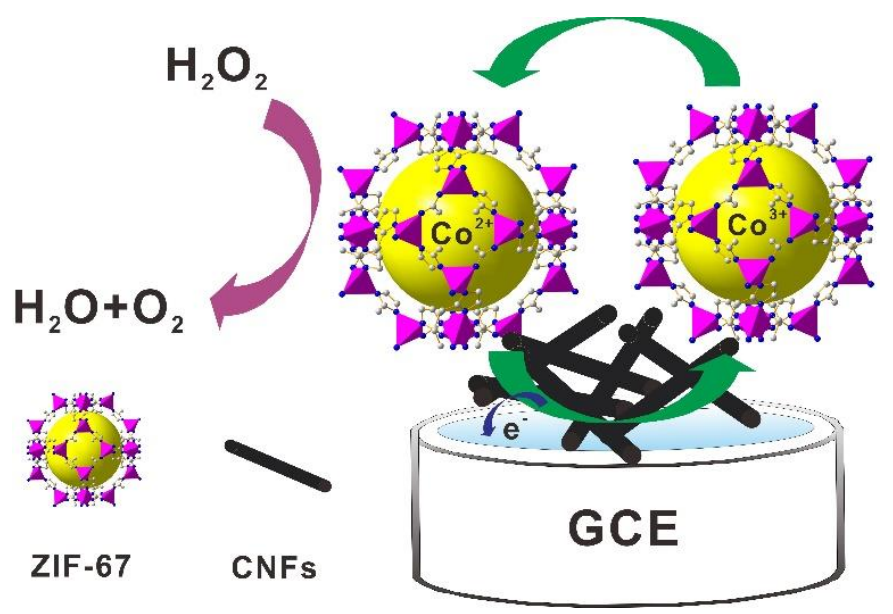

Scheme 2. Schematic illustration of the reduction of $\mathrm{H}_{2} \mathrm{O}_{2}$ by ZIF-67/CNFs/GCE in NaOH solution.

\subsection{Amperometric Response to $\mathrm{H}_{2} \mathrm{O}_{2}$}

The electroanalytical properties of ZIF-67/CNFs/GCE toward $\mathrm{H}_{2} \mathrm{O}_{2}$ were evaluated under $-0.2 \mathrm{~V}$. Figure 6a displays the chronoamperometric responses of ZIF-67/CNFs/GCE on successive addition of different volume of $\mathrm{H}_{2} \mathrm{O}_{2}$ solutions into $0.1 \mathrm{M} \mathrm{NaOH}$ solution. It can be seen from Figure 6a, with the successive addition of $\mathrm{H}_{2} \mathrm{O}_{2}$, the steady-state current values gradually increased. As shown in Figure 6b, the response current of the ZIF-67/CNFs/GCE showed a linear dependence on $\mathrm{H}_{2} \mathrm{O}_{2}$ concentration in the range from $2.5 \mu \mathrm{M}$ to $190 \mu \mathrm{M}$ with the linearity regression equation of $\Delta i(\mu \mathrm{A})=9.244+0.217 c(\mu \mathrm{M})\left(r^{2}=0.986\right)$, a sensitivity of $323 \mu \mathrm{A} \mathrm{mM} \mathrm{m}^{-1} \mathrm{~cm}^{-2}$, and a limit of detection (LOD) of $0.62 \mu \mathrm{M}(\mathrm{S} / \mathrm{N}=3)$. Besides, non-linear fitting was also applied to show that when the concentration of $\mathrm{H}_{2} \mathrm{O}_{2}$ was higher than $190 \mu \mathrm{M}$, the response current tended to be stable, suggesting a detection limit of the sensor.

The sensing performance of the ZIF-67/CNFs/GCE was next compared with other reported non-enzymatic $\mathrm{H}_{2} \mathrm{O}_{2}$ sensors, and the results are summarized in Table 1 . The prepared $\mathrm{H}_{2} \mathrm{O}_{2}$ sensor showed low detection limit, wide linear range, and high sensitivity, which are mainly attributed to excellent electrocatalytic activity of the ZIF-67/CNFs composite. 

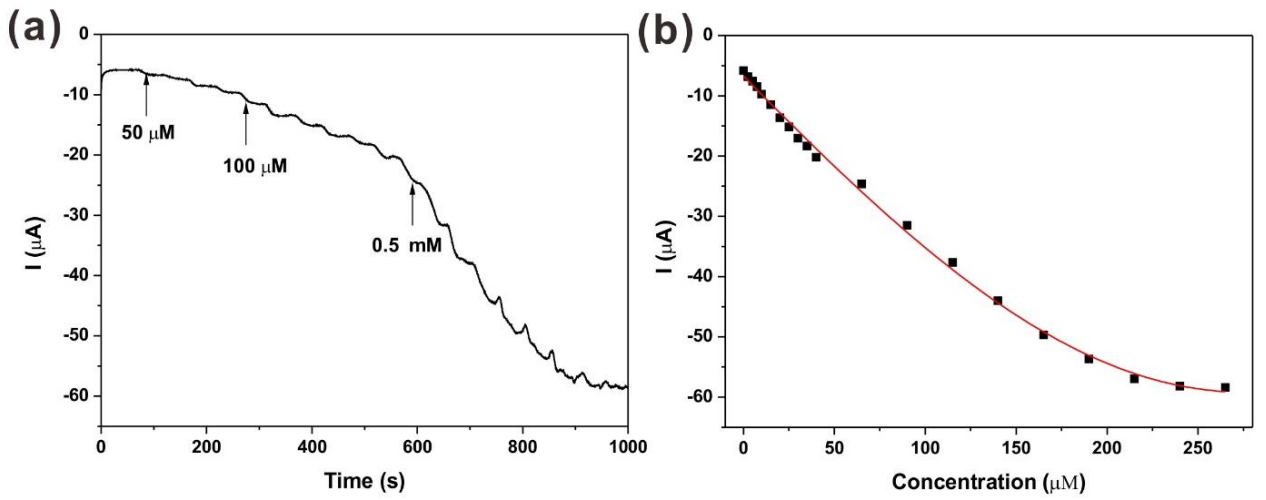

Figure 6. (a) Chronoamperometric responses of ZIF-67/CNFs/GCE on successive addition of different volume of $\mathrm{H}_{2} \mathrm{O}_{2}$ solutions into $0.1 \mathrm{M} \mathrm{NaOH}$ solution, applied potential: $-0.2 \mathrm{~V}$; (b) The calibration curves with nonlinear fitting.

Table 1. Sensing performance comparison of different non-enzymatic sensor toward $\mathrm{H}_{2} \mathrm{O}_{2}{ }^{1}$.

\begin{tabular}{ccccc}
\hline Electrode Description & $\begin{array}{c}\text { Detection Limit } \\
(\boldsymbol{\mu} \mathbf{M})\end{array}$ & $\begin{array}{c}\text { Linear Range } \\
(\mathbf{m M})\end{array}$ & $\begin{array}{c}\text { Sensitivity } \\
\left(\boldsymbol{\mu} \mathbf{A} \mathbf{~ m}^{-\mathbf{1}} \mathbf{c m}^{-\mathbf{2}} \mathbf{)}\right.\end{array}$ & Reference \\
\hline $\mathrm{Cu}-\mathrm{Ni}(\mathrm{OH})_{2} / \mathrm{GCE}$ & 1.5 & $0.005-0.14$ & 408 & {$[30]$} \\
$\mathrm{NP}-\mathrm{PtNi}$ & 1.0 & $0.01-0.18$ & - & {$[31]$} \\
$\mathrm{Co}_{3} \mathrm{O}_{4}-\mathrm{NWs} /$ carbon foam & 1.4 & $0.01-1.4$ & - & {$[32]$} \\
$\mathrm{Pt}$ nanoflower & 60 & $0.1-0.9$ & 104 & {$[33]$} \\
$\mathrm{Pt}-\mathrm{SnO}_{2} @ \mathrm{C}$ & 0.1 & $0.001-0.17$ & 241.1 & {$[34]$} \\
$\mathrm{ZIF}-67 / \mathrm{CNFs} / \mathrm{GCE}$ & 0.62 & $0.0025-0.19$ & 323 & This work \\
\hline
\end{tabular}

${ }^{1}$ The dashes in the table represent values that were not reported in the respective references.

\subsection{Reproducibility, Repeatability and Stability of the ZIF-67/CNFs/GCE}

The ZIF-67/CNFs/GCE showed satisfactory reproducibility, repeatability, and stability. Five electrochemical sensors were independently prepared under the same conditions, and the relative standard deviation (RSD) of the five modified electrodes was $2.7 \%$, indicating the electrochemical had good reproducibility.
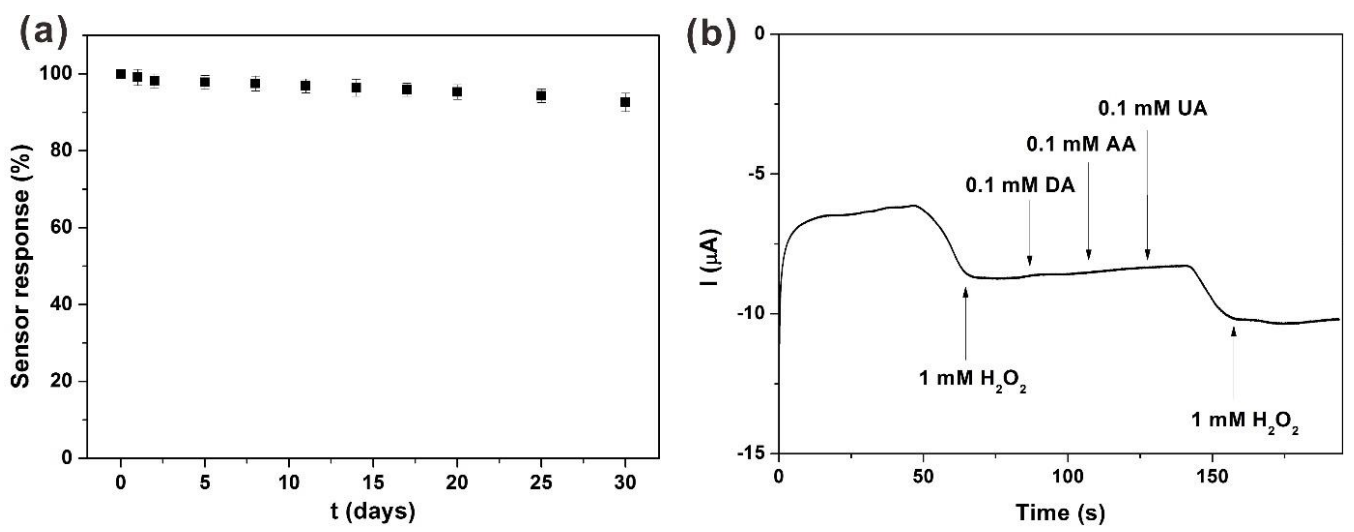

Figure 7. (a) Storage stability of the ZIF-67/CNFs/GCE in $0.1 \mathrm{M} \mathrm{NaOH}$ solution; (b) Chronoamperometric responses of ZIF-67/CNFs/GCE in $0.1 \mathrm{M} \mathrm{NaOH}$ solution at an applied potential of $-0.2 \mathrm{~V}$ with $1 \mathrm{mM}$ $\mathrm{H}_{2} \mathrm{O}_{2}+0.1 \mathrm{mM}$ DA + 0.1 mM AA + 0.1 mM UA.

The RSD of response currents of 10 successive measurements of the electrochemical sensor towards $\mathrm{H}_{2} \mathrm{O}_{2}$ was within $2.0 \%$, indicating satisfactory repeatability of the electrochemical sensor. Figure 7a shows the storage stability of the ZIF-67/CNFs/GCE in $0.1 \mathrm{M} \mathrm{NaOH}$ solution. After a week of storage in $0.1 \mathrm{M} \mathrm{NaOH}$ solution, the current response of the electrochemical sensor almost 
kept stable. The current response still retained $92.6 \%$ of the initial value through 30 days of storage, demonstrating that the electrochemical sensor based on ZIF-67/CNFs/GCE exhibited good stability.

\subsection{Anti-Interference and Real Sample Analysis}

In addition, the ZIF-67/CNFs/GCE sensor also displayed good anti-interference performance. As shown in Figure $7 \mathrm{~b}$, when adding $1 \mathrm{mM} \mathrm{H}_{2} \mathrm{O}_{2}$, the response current apparently changed, while it was barely affected by adding $0.1 \mathrm{mM}$ DA, $0.1 \mathrm{mM}$ AA, and $1.0 \mathrm{mM}$ UA. The favourable anti-interference performance can be attributed to the negative operating potential $(-0.2 \mathrm{~V})$ and the protection role of Nafion layer. Thus, the ZIF-67/CNFs/GCE sensor showed a good selectivity to $\mathrm{H}_{2} \mathrm{O}_{2}$. To demonstrate the practical application of the sensor, recovery experiments of $\mathrm{H}_{2} \mathrm{O}_{2}$ detection was carried out in milk samples, which were bought from a local supermarket, and the results are shown in Table 2. Five parallel experiments were conducted to study the recovery property of $\mathrm{H}_{2} \mathrm{O}_{2}$ in milk samples. It can be clearly observed that the recovery were all approach to $100 \%$, and the relative standard deviation (RSD) was only $1.5 \%$. All these data suggested that the $\mathrm{H}_{2} \mathrm{O}_{2}$ sensor based on ZIF-67/CNFs/GCE could be applied in analysis of $\mathrm{H}_{2} \mathrm{O}_{2}$ existing in beverage and food.

Table 2. Recovery experiment of detection of $\mathrm{H}_{2} \mathrm{O}_{2}$ in milk samples.

\begin{tabular}{ccccc}
\hline Sample & $\mathbf{C}_{\text {added }}(\mu \mathrm{M})$ & $\mathrm{C}_{\text {found }}(\boldsymbol{\mu M})$ & Recovery (\%) & RSD (\%) \\
\hline & & 99.5 & 99.5 & \\
\multirow{3}{*}{ Milk } & \multirow{4}{*}{100} & 102.3 & 102.3 & \\
& & 99.2 & 99.2 & \multirow{2}{*}{1.5} \\
& & 101.6 & 101.6 & \\
\hline
\end{tabular}

\section{Materials and Methods}

\subsection{Chemicals and Reagents}

Polyacrylonitrile (PAN, average molecular weight $=82,000)$ powder, $N, N$-dimethylformamide (DMF), methanol, 2-methylimidazole $\left(\mathrm{C}_{4} \mathrm{H}_{6} \mathrm{~N}_{2}, \mathrm{mIM}\right)$, cobalt nitrate hexahydrate $\left(\mathrm{Co}\left(\mathrm{NO}_{3}\right)_{2} \cdot 6 \mathrm{H}_{2} \mathrm{O}\right)$, potassium ferricyanide $\left(\mathrm{K}_{3}\left[\mathrm{Fe}(\mathrm{CN})_{6}\right]\right)$, potassium hexacyanoferrate $\left(\mathrm{K}_{4}\left[\mathrm{Fe}(\mathrm{CN})_{6}\right] \cdot 3 \mathrm{H}_{2} \mathrm{O}\right), \mathrm{NaOH}$, hydrogen peroxide $\left(\mathrm{H}_{2} \mathrm{O}_{2}\right)$, dopamine (DA), ascorbic acid (AA), and urea (UA) were all purchased from the Sinopharm Group Chemical Reagent Co., Ltd. (Shanghai, China). All chemicals were of analytical grade and used without further purification. Nafion (5\% w/w) was obtained from E. I. Du Pont Company (Wilmington, NC, USA). Besides, $0.1 \mathrm{M} \mathrm{NaOH}$ solution was used as a supporting electrolyte. All aqueous solutions were prepared with deionized water (DIW).

\subsection{Apparatus}

The morphology, elemental analysis, and chemical components of ZIF-67, CNFs, and ZIF-67/CNFs composite were respectively characterized by a field emission scanning electron microscope (FE-SEM, S4800, Hitachi, Tokyo, Japan), an energy dispersive X-ray spectroscopy (EDX, NORAN SYSTEM 7, Thermo Scientific, Carlsbad, CA, USA), and a Powder D8 Advance X-ray diffraction (XRD, AXS D8, Bruker, Coventry, UK). Electrochemical experiments were carried out using a CHI 660E electrochemical workstation (CH Instruments, Shanghai, China) at room temperature. The electrochemical measurements were implemented by a three-electrode cell with a GCE (4.0 mm in diameter, $12 \mathrm{~mm}^{2}$ in area, purchased from Gaoss Union Technology Co., Ltd., Wuhan, China), a platinum wire auxiliary electrode and an $\mathrm{Ag} / \mathrm{AgCl}$ reference electrode (saturated $\mathrm{KCl}$ ).

\subsection{Preparation of Carbon Nanofibers}

The carbon nanofibers (CNFs) were prepared by the following method. Firstly, 12 wt \% PAN powder, as precursor, was dissolved in DMF solution with $8 \mathrm{~h}$ of magnetic stirring to prepare the 
electrospinning solution. After that, the obtained solution was poured in a syringe for electrospinning with a flow rate of $1 \mathrm{~mL} / \mathrm{h}$, a voltage of $16 \mathrm{kV}$, and a working distance of $20 \mathrm{~cm}$, and respectively. Lastly, the final CNFs were prepared by carbonizing the PAN nanofibers through a high temperature furnace. The whole procedure was carried out in $\mathrm{Ar}$ atmosphere and can be summarized as follows: (1) heating up to $280^{\circ} \mathrm{C}$ with a heating rate of $2{ }^{\circ} \mathrm{C} \mathrm{min}-1$, maintaining this temperature for $1 \mathrm{~h}$ to complete the pre oxidation treatment of nanofibers; (2) heating up to $900{ }^{\circ} \mathrm{C}$ at the rate of $5{ }^{\circ} \mathrm{C} \mathrm{min}-1$, keeping this temperature for $2 \mathrm{~h}$ to carbonize the nanofibers. The obtained carbon nanofibrous membrane was further ground to powder (short carbon nanofibers) for the following experiments.

\subsection{Synthesis of ZIF-67/CNFs Composite}

In this study, $\mathrm{Co}\left(\mathrm{NO}_{3}\right)_{2} \cdot 6 \mathrm{H}_{2} \mathrm{O}$ and mIM were used as precursors to produce $\mathrm{ZIF}-67$ nanocrystals. First of all, the CNFs and $\mathrm{Co}\left(\mathrm{NO}_{3}\right)_{2} \cdot 6 \mathrm{H}_{2} \mathrm{O}$ (with the mass ratio of 1:1) were dispersed in $40 \mathrm{~mL}$ of methanol with slight stirring for $1 \mathrm{~h}$ at $45^{\circ} \mathrm{C}$. After that, above solution was added into $40 \mathrm{~mL}$ of $2 \mathrm{~mol} \mathrm{~L}^{-1} \mathrm{mIM}$ methanol solution. The solution gradually became purple and was incubated for $24 \mathrm{~h}$ at room temperature. The obtained products were gathered, washed for several times with ethanol and collected by centrifugation. For comparison, pure ZIF-67 nanocrystals were prepared by similar procedure except from the addition of CNFs.

\subsection{Preparation of Electrochemical Sensors}

Considering the optimal response and stability of modified electrode, among control-experiments, the concentration and mass ratio of Nafion and ZIF-67/CNFs were optimized. Ultimately, the electrochemical sensor was prepared by the mixture containing $1 \mathrm{wt} \%$ Nafion, and $1 \mathrm{mg} \mathrm{mL} \mathrm{mL}^{-1} \mathrm{ZIF}-67 / \mathrm{CNFs}$.

The preparation process of the ZIF-67/CNFs modified GCE (ZIF-67/CNFs/GCE) is as follows: Firstly, $1 \mathrm{mg}$ ZIF-67/CNFs composites were added into $1 \mathrm{~mL}$ DIW to prepare ZIF-67/CNFs suspension under continuous stirring. Afterward, a mixture containing ZIF-67/CNFs suspension and a certain volume of Nafion ( $5 \mathrm{wt} \%$ ) were stirred for $1 \mathrm{~h}$. Lastly, the ZIF-67/CNFs/GCE was prepared by dropping $10 \mu \mathrm{L}$ of the mixture on the surface of processed GCE, which was polished by alumina followed by rinsing and ultrasonicating with DIW.

For comparison experiments, CNFs-modified GCE (CNFs/GCE) and ZIF-67 modified GCE (ZIF-67/GCE) were respectively prepared through the same methods by keeping the same amount of CNFs, ZIF-67, and ZIF-67/CNFs composite. All the electrodes were immersed in $0.1 \mathrm{M} \mathrm{NaOH}$ solution for $20 \mathrm{~min}$ to remove the impurities before experiment. For the electrochemical impedance spectroscopy (EIS) characterization, the CNFs modified GCE, ZIF-67 modified GCE, and ZIF-67/CNFs modified GCE were fabricated by dropping $10 \mu \mathrm{L} 1 \mathrm{mg} \mathrm{mL}^{-1}$ of CNFs, ZIF-67, and ZIF-67/CNFs suspension in DIW without Nafion on the GCE surface, followed by drying in Ar atmosphere.

\section{Conclusions}

In summary, a ZIF-67/CNFs composite was synthesized by a "one pot" method, and a novel non-enzymatic $\mathrm{H}_{2} \mathrm{O}_{2}$ sensor made of ZIF-67/CNFs has been successfully fabricated. The ZIF-67/CNFs/GCE exhibited enhanced electrocatalytic performance towards $\mathrm{H}_{2} \mathrm{O}_{2}$ in comparison with ZIF-67/GCE due to the accelerated electron transfer rate by CNFs. Besides, the sensor displayed low detection limit, high sensitivity, as well as satisfactory selectivity and long-term stability. Moreover, the sensor was successfully applied in the detection of $\mathrm{H}_{2} \mathrm{O}_{2}$ in milk. This study not only demonstrates the application potential of the ZIF-67/CNFs composite in constructing high-performance non-enzymatic $\mathrm{H}_{2} \mathrm{O}_{2}$ sensor, but also provides an idea for improving the electrocatalytic activity of MOF materials.

Author Contributions: Y.F. and Y.Z. conceived the experiments; J.D. and Y.G. carried out the samples preparation and performance tests; Y.F. and J.D. wrote the original draft; H.K. and W.Z. revised the paper. 
Funding: This research was funded by the National Natural Science Foundation of China $(51803094,51803095)$, the Natural Science Research Project of Jiangsu Higher Education Institutions (17KJB540002), the Nantong Science and Technology Project (MS12016020), the Nantong University Scientific Research Fund (17R19), the Open Project Program of Fujian Key Laboratory of Novel Functional Textile Fibers and Materials, Minjiang University (FKLTFM1702), and the Student Innovation and Entrepreneurship Training Project of Jiangsu Province (201710304109X).

Conflicts of Interest: The authors declare no conflict of interest.

\section{References}

1. Liu, W.F.; Zhou, Z.H.; Yin, L.; Zhu, Y.M.; Zhao, J.; Zhu, B.; Zheng, L.B.; Jin, Q.; Wang, L. A novel self-powered bioelectrochemical sensor based on $\mathrm{CoMn}_{2} \mathrm{O}_{4}$ nanoparticle modified cathode for sensitive and rapid detection of hydrogen peroxide. Sensor Actuat. B-Chem. 2018, 271, 247-255. [CrossRef]

2. Singh, S.; Singh, M.; Mitra, K.; Singh, R.; Sen Gupta, S.K.; Tiwari, I.; Ray, B. Electrochemical sensing of hydrogen peroxide using brominated graphene as mimetic catalase. Electrochim. Acta 2017, 258, 1435-1444. [CrossRef]

3. Peng, C.; Zhou, S.Y.; Zhang, X.M.; Zeng, T.Q.; Zhang, W.; Li, H.M.; Liu, X.Y.; Zhao, P. One pot synthesis of nitrogen-doped hollow carbon spheres with improved electrocatalytic properties for sensitive $\mathrm{H}_{2} \mathrm{O}_{2}$ sensing in human serum. Sensor Actuat. B-Chem. 2018, 270, 530-537. [CrossRef]

4. Fu, Y.M.; Huang, D.; Li, C.M.; Zou, L.N.; Ye, B.X. Graphene blended with $\mathrm{SnO}_{2}$ and Pd-Pt nanocages for sensitive nonenzymatic electrochemical detection of $\mathrm{H}_{2} \mathrm{O}_{2}$ released from living cells. Anal. Chim. Acta 2018, 1014, 10-18. [CrossRef] [PubMed]

5. Jiang, X.Y.; Wang, H.J.; Yuan, R.; Chai, Y.Q. Functional Three-Dimensional Porous Conductive Polymer Hydrogels for Sensitive Electrochemiluminescence in Situ Detection of $\mathrm{H}_{2} \mathrm{O}_{2}$ Released from Live Cells. Anal. Chem. 2018, 90, 8462-8469. [CrossRef] [PubMed]

6. Zhou, J.X.; Tang, L.N.; Yang, F.; Liang, F.X.; Wang, H.; Li, Y.T.; Zhang, G.J. $\mathrm{MoS}_{2} /$ Pt nanocompositefunctionalized micro-needle for real-time monitoring of hydrogen peroxide release from living cells. Analyst 2017, 142, 4322-4329. [CrossRef] [PubMed]

7. Zhang, L.S.; Wong, G.T. Optimal conditions and sample storage for the determination of $\mathrm{H}_{2} \mathrm{O}_{2}$ in marine waters by the scopoletin-horseradish peroxidase fluorometric method. Talanta 1999, 48, 1031-1038. [CrossRef]

8. Gimeno, P.; Bousquet, C.; Lassu, N.; Maggio, A.F.; Civade, C.; Brenier, C.; Lempereur, L. High-performance liquid chromatography method for the determination of hydrogen peroxide present or released in teeth bleaching kits and hair cosmetic products. J. Pharm. Biomed. Anal. 2015, 107, 386-393. [CrossRef] [PubMed]

9. Klassen, N.V.; Marchington, D.; Mcgowan, H.C.E. $\mathrm{H}_{2} \mathrm{O}_{2}$ Determination by the I3-Method and by $\mathrm{KMnO}_{4}$ Titration. Anal. Chem. 1994, 66, 2921-2925. [CrossRef]

10. Li, D.; Luo, L.; Pang, Z.; Chen, X.; Cai, Y.; Wei, Q. Amperometric detection of hydrogen peroxide using a nanofibrous membrane sputtered with silver. RSC Adv. 2013, 4, 3857-3863. [CrossRef]

11. Treadaway, V.; Heikes, B.G.; McNeill, A.S.; Silwal, I.K.C.; O'Sullivan, D.W. Measurement of formic acid, acetic acid and hydroxyacetaldehyde, hydrogen peroxide, and methyl peroxide in air by chemical ionization mass spectrometry: airborne method development. Atmos. Meas. Tech. 2018, 11, 1901-1920. [CrossRef]

12. Zhang, B.; Zhang, X.; Huang, D.; Li, S.; Yuan, H.; Wang, M.; Shen, Y. Cog $\mathrm{S}_{8}$ hollow spheres for enhanced electrochemical detection of hydrogen peroxide. Talanta 2015, 141, 73-79. [CrossRef] [PubMed]

13. Wang, Z.; Xie, F.; Liu, Z.; Du, G.; Asiri, A.M.; Sun, X. High-Performance Non-Enzyme Hydrogen Peroxide Detection in Neutral Solution: Using a Nickel Borate Nanoarray as a 3D Electrochemical Sensor. Chemistry 2017, 23, 16179-16183. [CrossRef] [PubMed]

14. Sun, X.; Guo, S.; Liu, Y.; Sun, S. Dumbbell-like PtPd-Fe $\mathrm{O}_{4}$ nanoparticles for enhanced electrochemical detection of $\mathrm{H}_{2} \mathrm{O}_{2}$. Nano Lett. 2012, 12, 4859-4863. [CrossRef] [PubMed]

15. Huang, J.; Zhu, Y.; Zhong, H.; Yang, X.; Li, C. Dispersed CuO nanoparticles on a silicon nanowire for improved performance of nonenzymatic $\mathrm{H}_{2} \mathrm{O}_{2}$ detection. ACS Appl. Mater. Interfaces 2014, 6, 7055-7062. [CrossRef] [PubMed]

16. Wang, Y.; Cao, W.; Wang, L.; Zhuang, Q.; Ni, Y. Electrochemical determination of 2,4,6-trinitrophenol using a hybrid film composed of a copper-based metal organic framework and electroreduced graphene oxide. Microchim. Acta 2018, 185, 315-323. [CrossRef] [PubMed] 
17. Zhou, Y.; Li, C.; Hao, Y.; Ye, B.; Xu, M. Oriented growth of cross-linked metal-organic framework film on graphene surface for non-enzymatic electrochemical sensor of hydrogen peroxide in disinfectant. Talanta 2018, 188, 282-287. [CrossRef] [PubMed]

18. Gao, C.Y.; Tian, H.R.; Ai, J.; Li, L.J.; Dang, S.; Lan, Y.Q.; Sun, Z.M. A microporous Cu-MOF with optimized open metal sites and pore spaces for high gas storage and active chemical fixation of $\mathrm{CO}_{2}$. Chem. Commun. 2018, 54, 7093-7094. [CrossRef] [PubMed]

19. Lian, X.Z.; Huang, Y.Y.; Zhu, Y.Y.; Fang, Y.; Zhao, R.; Joseph, E.; Li, J.L.; Pellois, J.P.; Zhou, H.C. Enzyme-MOF Nanoreactor Activates Nontoxic Paracetamol for Cancer Therapy. Angew. Chem. Int. Ed. 2018, 57, 5725-5730. [CrossRef] [PubMed]

20. Liang, X.-X.; Wang, N.; Qu, Y.-L.; Yang, L.-Y.; Wang, Y.-G.; Ouyang, X.-K. Facile Preparation of Metal-Organic Framework (MIL-125)/Chitosan Beads for Adsorption of Pb(II) from Aqueous Solutions. Molecules 2018, 23, 1524. [CrossRef] [PubMed]

21. Wan, M.M.; Zhang, X.L.; Li, M.Y.; Chen, B.; Yin, J.; Jin, H.C.; Lin, L.; Chen, C.; Zhang, N. Hollow Pd/MOF Nanosphere with Double Shells as Multifunctional Catalyst for Hydrogenation Reaction. Small 2017, 13, 6. [CrossRef] [PubMed]

22. Jiang, X.X.; Zhao, C.J.; Zhong, C.J.; Li, J.P. The Electrochemical Sensors Based on MOF and Their Applications. Prog. Chem. 2017, 29, 1206-1214.

23. Ni, Y.; Liao, Y.; Zheng, M.B.; Shao, S.J. In-situ growth of $\mathrm{Co}_{3} \mathrm{O}_{4}$ nanoparticles on mesoporous carbon nanofibers: a new nanocomposite for nonenzymatic amperometric sensing of $\mathrm{H}_{2} \mathrm{O}_{2}$. Microchim. Acta 2017, 184, 3689-3695. [CrossRef]

24. Phan, A.; Doonan, C.J.; Uriberomo, F.J.; Knobler, C.B.; O’Keeffe, M.; Yaghi, O.M. Synthesis, structure, and carbon dioxide capture properties of zeolitic imidazolate frameworks. Acc. Chem. Res. 2010, 43, 58-67. [CrossRef] [PubMed]

25. Li, C.; Wu, R.; Zou, J.; Zhang, T.; Zhang, S.; Zhang, Z.; Hu, X.; Yan, Y.; Ling, X. MNPs@anionic MOFs/ERGO with the size selectivity for the electrochemical determination of $\mathrm{H}_{2} \mathrm{O}_{2}$ released from living cells. Biosens. Bioelectron. 2018, 116, 81-88. [CrossRef] [PubMed]

26. Vamvakaki, V.; Tsagaraki, K.; Chaniotakis, N. Carbon nanofiber-based glucose biosensor. Anal. Chem. 2006, 78, 5538-5542. [CrossRef] [PubMed]

27. Hou, X.B.; Zhou, H.M.; Zhang, J.; Cai, Y.B.; Huang, F.L.; Wei, Q.F. High Adsorption Pearl-Necklace-Like Composite Membrane Based on Metal-Organic Framework for Heavy Metal Ion Removal. Part. Part. Syst. Char. 2018, 35, 1700438-1700445. [CrossRef]

28. Li, D.; Yang, J.; Zhou, J.; Wei, Q.; Huang, F. Direct electrochemistry of laccase and a hydroquinone biosensing application employing ZnO loaded carbon nanofibers. RSC Adv. 2014, 4, 61831-61840. [CrossRef]

29. Lin, K.Y.; Chang, H.A. Ultra-high adsorption capacity of zeolitic imidazole framework-67 (ZIF-67) for removal of malachite green from water. Chemosphere 2015, 139, 624-631. [CrossRef] [PubMed]

30. Gu, A.; Wang, G.; Jing, G.; Zhang, X.; Fang, B. An unusual $\mathrm{H}_{2} \mathrm{O}_{2}$ electrochemical sensor based on $\mathrm{Ni}(\mathrm{OH})_{2}$ nanoplates grown on Cu substrate. Electrochim. Acta 2010, 55, 7182-7187. [CrossRef]

31. Xu, C.; Wang, J.; Zhou, J. Nanoporous PtNi alloy as an electrochemical sensor for ethanol and $\mathrm{H}_{2} \mathrm{O}_{2}$. Sens. Actuat. B-Chem. 2013, 182, 408-415. [CrossRef]

32. Liu, M.; He, S.; Chen, W. $\mathrm{Co}_{3} \mathrm{O}_{4}$ nanowires supported on $3 \mathrm{D} \mathrm{N}$-doped carbon foam as an electrochemical sensing platform for efficient $\mathrm{H}_{2} \mathrm{O}_{2}$ detection. Nanoscale 2014, 6, 11769-11776. [CrossRef] [PubMed]

33. Wan, J.; Wang, W.; Yin, G.; Ma, X. Nonenzymatic $\mathrm{H}_{2} \mathrm{O}_{2}$ Sensor Based on Pt Nanoflower Electrode. J. Clust. Sci. 2012, 23, 1061-1068. [CrossRef]

34. Lu, H.; Yu, S.; Fan, Y.; Yang, C.; Xu, D. Nonenzymatic hydrogen peroxide electrochemical sensor based on carbon-coated $\mathrm{SnO}_{2}$ supported Pt nanoparticles. Colloid Surface B 2013, 101, 106-110. [CrossRef] [PubMed]

Sample Availability: Samples of the compounds are not available from the authors. 